Article

\title{
Experimental Investigation on Uniaxial Compression Mechanical Behavior and Damage Evolution of Pre-Damaged Granite after Cyclic Loading
}

\author{
Jianhua Hu (D), Pingping Zeng (D), Dongjie Yang *, Guanping Wen, Xiao Xu, Shaowei Ma, Fengwen Zhao $\mathbb{D}^{(D)}$ and \\ Rui Xiang
}

check for

updates

Citation: Hu, J.; Zeng, P.; Yang, D.; Wen, G.; Xu, X.; Ma, S.; Zhao, F.;

Xiang, R. Experimental Investigation on Uniaxial Compression Mechanical Behavior and Damage Evolution of Pre-Damaged Granite after Cyclic Loading. Energies 2021, 14, 6179. https://doi.org/10.3390/en14196179

Academic Editor: Kamel Hooman

Received: 13 August 2021

Accepted: 23 September 2021

Published: 28 September 2021

Publisher's Note: MDPI stays neutral with regard to jurisdictional claims in published maps and institutional affiliations.

Copyright: (c) 2021 by the authors. Licensee MDPI, Basel, Switzerland. This article is an open access article distributed under the terms and conditions of the Creative Commons Attribution (CC BY) license (https:// creativecommons.org/licenses/by/ $4.0 /)$.
School of Resources and Safety Engineering, Central South University, Changsha 410083, China; hujh21@csu.edu.cn (J.H.); 195512084@csu.edu.cn (P.Z.); Guanping-Wen@csu.edu.cn (G.W.); xiaoxu@csu.edu.cn (X.X.); mashaowei@csu.edu.cn (S.M.); zhaofengwen@csu.edu.cn (F.Z.); ruitorres@csu.edu.cn (R.X.)

* Correspondence: yangdjxx@csu.edu.cn

\begin{abstract}
Failure behavior of pillars in deep mines is affected by various cyclic loads that cause initial pre-damage. Pillars will be further damaged and developed in the long-term compressive stress until they are destroyed. To reveal the strength characteristics and crack damage fracture laws after rock pre-damage, uniaxial compression tests were carried out on granite specimens damaged by cyclic loading using the digital speckle correlation method. The experimental results indicate that the mechanical properties of pre-damaged specimens show large damage differences for different cycles. The damage variable of the pre-damaged specimens increases with the increase of cycle number and confining pressure. The damage of specimens is primarily due to the strength weakening effect caused by cycle numbers, and the confining pressure restriction effect is not obvious. The evolution laws of uniaxial compression damage propagation in the pre-damaged specimens show differences and obvious localization phenomenon. Pre-damaged specimens experienced three failure modes in the uniaxial compression test, namely tensile shear failure (Mode I), quasi-coplanar shear failure (Mode II), and stepped path failure (Mode III), and under different pre-damage stress environments with high confining pressures, the failure modes are dominated by Mode II and Mode III, respectively.
\end{abstract}

Keywords: digital speckle correlation method; cyclic load; high confining pressure; damage evolution; failure mode

\section{Introduction}

Instability in rock engineering is primarily due to the further expansion of joints, faults, and cracks [1]. There are studies that show the effect of mechanical excavation as a cyclic load in deep mining, especially with roadheader excavation [2], which will lead to stress redistribution on pillars or surrounding rocks. At the same time, the rock masses are subjected to cyclic loading, causing meso-damage of the surrounding rock or pillars [3]. Mechanical properties for permanently supported pillars are further damaged and deteriorated under compressive stress after excavation, which introduces safety hazards to the engineering structure [4].

In recent years, rock mass damage evolution research has made significant achievements. Fan et al. [5] conducted uniaxial compression tests on specimens containing multinon-persistent joints with $\mathrm{PFC}^{3 \mathrm{D}}$, and they found that the joint specimens exhibited four failure modes. Hu et al. [6] proposed an interval value for the damage initial stress range of intact rocks under uniaxial compression. Xiao et al. [7] presented the fatigue damage evolution laws of rocks under cyclic loading and believed that it primarily depended on the maximum stress, amplitude, and initial fatigue damage. Bagde et al. [8] studied the effects of amplitude and frequency on the mechanical properties of rock under uniaxial cyclic 
loading, and the average Young's modulus and dynamic axial stiffness of the rock was found to decrease with loading frequency and amplitude. Chen et al. [9] analyzed the crack propagation laws of the granite in three fatigue stages during uniaxial cyclic loading, and the results showed that distinguishing crack growth was identified in quartz grains at the initial degradation stage. At the second stage, no significant crack growth in quartz grains was identified. On the other hand, in feldspar grains, development of cracks was observed. At the final accelerated stage, many intergranular cracks were identified. Zhang et al. [10] carried out uniaxial cyclic loading tests on cracked rock. The results showed that the damage mechanism was caused by the initiation, propagation, and penetration of cracks. Fuenkajorn et al. [11] found that the compressive strength of salt rocks under cyclic loading decreased as the cycle numbers increased. Taheri et al. [12] studied the crack evolution laws in the Hawkesbury sandstone under different cyclic loading and found that unstable cracks propagation occurred at around $65 \%$ of the cumulative axial strain. Jia et al. [13] studied the relationship of deformation parameters to the cycle numbers of fine-grained sandstone under triaxial cyclic loading. The experimental results showed that the axial and lateral irreversible strain initially increased with a decreasing rate, followed by steady state increases, before failure within a given stress level. When the specimens approached failure, an accelerated increase in the irreversible strain occurred. Wang et al. [14] studied the effects of volumetric change on the granite fatigue performances under triaxial cyclic loading (confining pressure was 3-10 MPa), and they found that the stress level corresponding to the transition from volumetric compaction to volumetric dilation could be considered as the threshold for fatigue failure. Liu et al. [15] studied the effects of the confining pressure (2-50 MPa) and frequencies on the sandstone damage evolution during cyclic loading and unloading. The results showed that with an increase in the frequency, the axial strain and the number of cycles at failure increased at the same confining pressure. On research methods, the digital speckle correlation method (DSCM) is helpful for analyzing the local deformation and instability of the intact rock mechanics experiment process and has become an important method for studying the local deformation of geotechnical materials [16]. Xie et al. [17] observed the strain field on coal-rock composites with various height ratios using DSCM under uniaxial compression, and they determined that the strain cloud gradient and local strain area move upward and increase with increasing coal rock height. Tan et al. [18] discussed the influences of crack numbers on the local deformation of layer-crack rock models by using the DSCM technique in uniaxial compression tests. Based on speckle images, they found that with the increase of fissure number of layer-crack specimens, the bearing capacity of specimens decreased, and the appearing time of nonuniform deformation phenomenon in the specimen surface decreased. Sun et al. [19] combined uniaxial compression tests with DSCM to research deformation field evolution laws of backfill specimens. The results showed that the peak strain of the GCGFB specimen was large, and the failure characteristics of the GCGFB sample showed multiple shear deformation zones, which is indicative of a typical cylindrical splitting failure. Cao et al. [20] used DSCM and the numerical methods in $\mathrm{PFC}^{2 \mathrm{D}}$ to analysis the failure behavior of brittle jointed specimens during uniaxial loading. They divided the failure modes into three categories: stepped path failure, failure through parallel plane, and failure through cross plane.

However, these research results rarely involve the cyclic damage law of rock under high confining pressure. As for the damaged rock in deep high stress field under cyclic loading, after excavation, the three-dimensional stress changes to two-dimensional stress, and the research on its mechanical behavior and damage law is rare. On the other hand, the granite has the characteristics of good stability and low permeability, and in deep mining, some orebodies occur near granite, so the damage research of granite under cyclic load is particularly important. This paper primarily studied the damage state of rocks under the long-term action of in situ stress in the depth of 1852-4444 $\mathrm{m}$ (in situ stress between 50-120 MPa) [21]. Uniaxial stress-resistance tests were conducted on granite specimens with various cyclic loading numbers, and the strength characteristics, damage evolution, 
and failure modes of pre-damaged granite specimens were analyzed in combination with DSCM, providing the theoretical basis for a mechanical analysis in deep mines.

\section{Experiment}

\subsection{Equipment}

The main equipment used was the American MTS815 triaxial electro-hydraulic testing machine, the vacuum water-saturation equipment, the uniaxial compression rigidity testing machine, and the DSCM acquisition system (Figure 1). The camera type of the DSCM system is WP-UT500M, with a resolution of 5 million pixels, a rate of $20 \mathrm{frames} / \mathrm{s}$, an image size of 2448 pixels $\times 2048$ pixels, and a fluorescent light source.

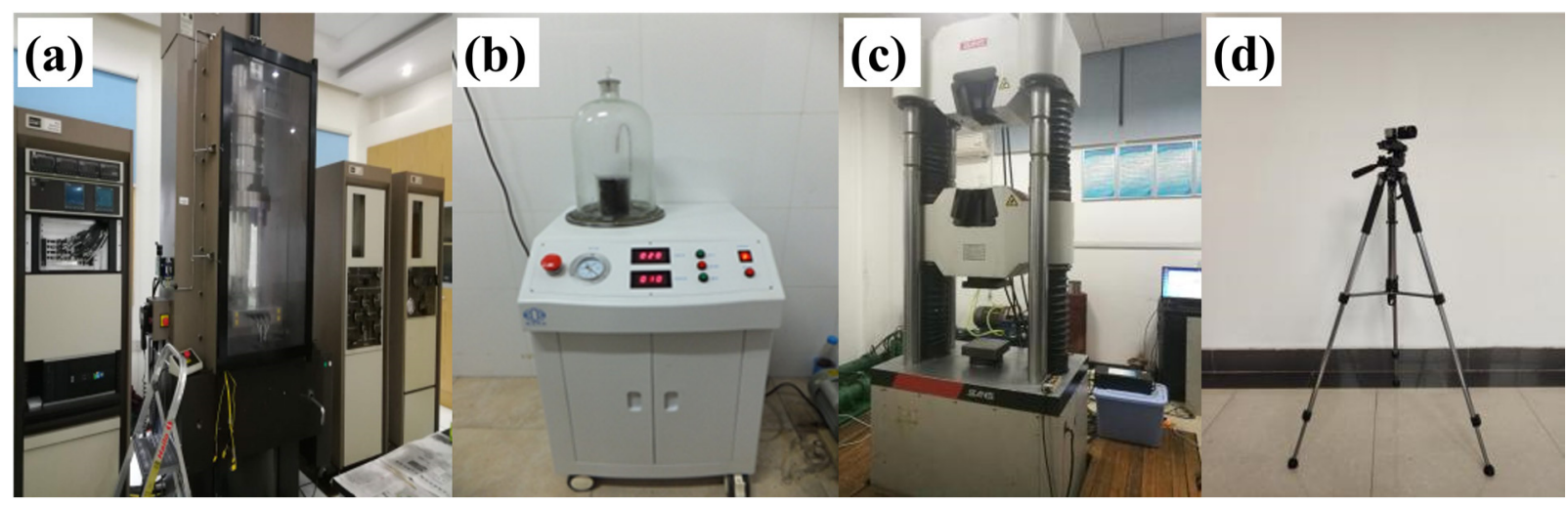

Figure 1. Experimental equipment. (a) MTS815 testing machine for $2000 \mathrm{KN}$; (b) rock water-saturation equipment; (c) uniaxial compression rigidity testing machine; (d) DSCM acquisition system.

\subsection{Experimental Scheme}

\subsubsection{Pre-Damage Treatment of Specimens}

The granite specimen was a standard cylinder of $50 \mathrm{~mm} \times 100 \mathrm{~mm}$, with uniform dense texture and no damage. To obtain the pre-damaged granite specimens, the intact specimens were first subjected to a triaxial compression test. The cyclic loading scheme is shown in Figure 2. The granites were classified into four groups (A, B, C, and D), and the basic physical parameters of group A3, B3, C3, and D are shown in Table 1. The procedures are mainly as follows:

1. Four groups of rock specimens were vacuumed and saturated with water using the vacuum water saturation equipment, first for $240 \mathrm{~min}$ dry pumping and then for 120 min wet pumping to completely saturate the specimens;

2. Uniaxial compressive strength of specimens in Group D were measured with the MTS815 testing machine loaded at a rate of $2 \mathrm{kN} / \mathrm{s}$ (Group D was the control group);

3. The remaining rock specimens of Group A, B, and C were cyclically loaded and unloaded for 10, 20, and 30 times under confining pressures of $50 \mathrm{MPa}, 80 \mathrm{MPa}$, $100 \mathrm{MPa}$, and $120 \mathrm{MPa}$, respectively, without destroying the specimens, to realize the pre-damage treatment inside the granite specimens (see Table 2 for the specific scheme). The load cycle path used constant confining pressure and unloading axial pressure; both loading and unloading rates were $2 \mathrm{kN} / \mathrm{s}$, loading stress point was $153 \mathrm{MPa}$ (about $93 \%$ of the average uniaxial compressive strength), and unloading stress point was $5 \mathrm{MPa}$ (about $3 \%$ of the average uniaxial compressive strength). 


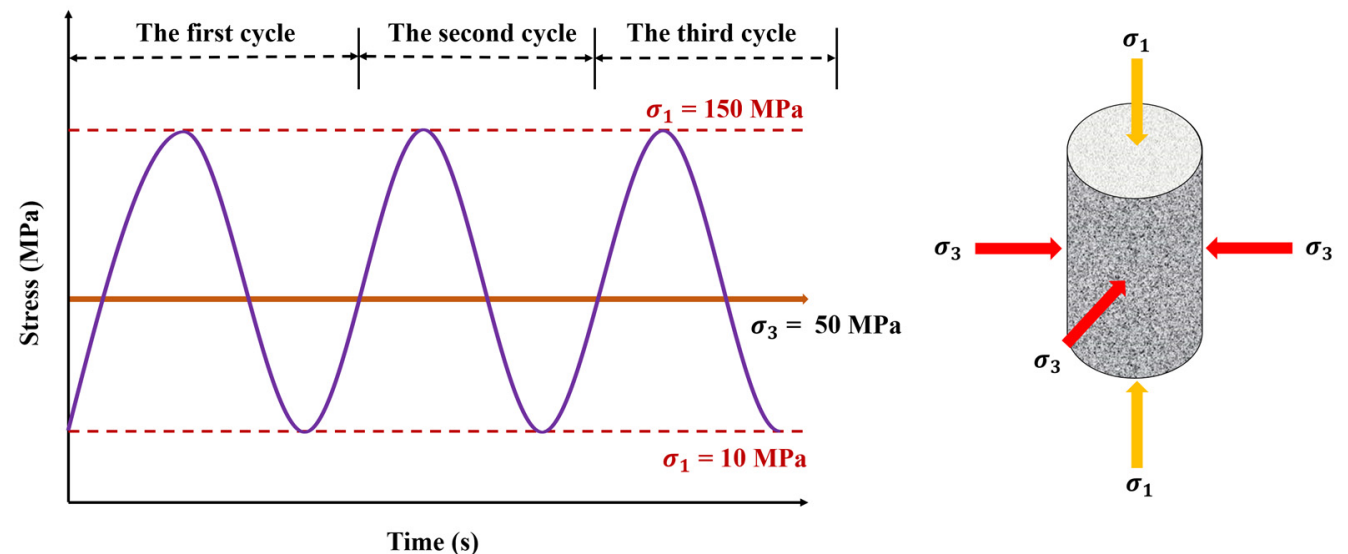

Figure 2. Cyclic loading scheme.

Table 1. Physical parameters of granite specimens.

\begin{tabular}{|c|c|c|c|c|c|c|c|}
\hline Group & $\begin{array}{c}\text { Number of } \\
\text { Cycles }\end{array}$ & $\begin{array}{l}\text { Height } \\
\text { (mm) }\end{array}$ & $\begin{array}{l}\text { Diameter } \\
(\mathrm{mm})\end{array}$ & Dry Mass (g) & $\begin{array}{l}\text { Natural } \\
\text { Mass (g) }\end{array}$ & $\begin{array}{l}\text { Saturated } \\
\text { Mass (g) }\end{array}$ & $\begin{array}{l}\text { Saturated Mass } \\
\text { after Load (g) }\end{array}$ \\
\hline A3-1 & & 100.67 & 49.11 & 495.25 & 495.79 & 496.58 & 497.20 \\
\hline A3-2 & 10 & 101.01 & 49.12 & 492.53 & 493.02 & 493.91 & 499.00 \\
\hline A3-3 & & 100.30 & 48.91 & 491.73 & 492.17 & 493.03 & 497.62 \\
\hline B3-1 & & 100.17 & 49.34 & 493.82 & 494.49 & 495.35 & 497.42 \\
\hline B3-2 & 20 & 100.45 & 49.05 & 494.89 & 495.54 & 496.51 & 497.02 \\
\hline B3-3 & & 100.43 & 49.45 & 498.07 & 498.61 & 499.54 & 502.21 \\
\hline C3-1 & & 100.95 & 49.04 & 494.66 & 495.20 & 496.02 & 496.68 \\
\hline C3-2 & 30 & 100.30 & 49.59 & 502.68 & 503.24 & 504.73 & 504.77 \\
\hline C3-3 & & 100.75 & 49.16 & 496.48 & 497.02 & 497.96 & 498.56 \\
\hline D-1 & & 100.50 & 49.12 & 492.24 & 492.74 & 493.65 & - \\
\hline D-2 & 0 & 100.77 & 49.04 & 495.15 & 495.73 & 496.61 & - \\
\hline D-3 & & 99.45 & 49.17 & 491.03 & 491.57 & 492.40 & - \\
\hline
\end{tabular}

Table 2. Specific scheme of pre-damage tests.

\begin{tabular}{|c|c|c|c|c|}
\hline \multirow{2}{*}{$\begin{array}{l}\text { Confining Pressure } \\
\text { (MPa) }\end{array}$} & \multicolumn{3}{|c|}{ Cyclic Loading and Unloading of Specimens } & \multirow{2}{*}{$\begin{array}{c}\text { Uniaxial Compression } \\
\text { Specimens }\end{array}$} \\
\hline & 10 Cycles & 20 Cycles & 30 Cycles & \\
\hline \multirow{3}{*}{50} & A1-1 & B1-1 & C1-1 & \multirow{12}{*}{$\begin{array}{l}\text { D-1 } \\
\text { D-2 } \\
\text { D-3 }\end{array}$} \\
\hline & A1-2 & B1-2 & C1-2 & \\
\hline & A1-3 & B1-3 & C1-3 & \\
\hline & A2-1 & B2-1 & C2-1 & \\
\hline \multirow{3}{*}{80} & A2-2 & B2-2 & C2-2 & \\
\hline & A2-3 & $\mathrm{B} 2-3$ & C2-3 & \\
\hline & A3-1 & B3-1 & C $3-1$ & \\
\hline \multirow[t]{3}{*}{100} & A3-2 & B3-2 & C3-2 & \\
\hline & A3-3 & B3-3 & C3-3 & \\
\hline & A4-1 & B4-1 & C4-1 & \\
\hline \multirow[t]{2}{*}{120} & A4-2 & B4-2 & C4-2 & \\
\hline & A4-3 & B4-3 & C4-3 & \\
\hline
\end{tabular}

\subsubsection{Uniaxial Compression Test with DSCM}

The fundamentals of DSCM is to match the same pixel areas (sub-images) between two digital speckle images of the specimen's surface before deformation (reference image) and after deformation (deformed image) [22]. Its main purpose is to search the displacement component of the pixels in the speckle sub-image (Figure 3). To identify the sub-images in the two images, the properties of the sub-images are represented by the gray function. Thus, by tracking the grayscale value of each pixel in the reference image and the deformation 
image and evaluating their image correlation, the displacement field on the specimen's surface can be calculated, and then the strain field can be obtained by further calculation. The correlation coefficient is defined as follows [23]:

$$
C(u, v)=\frac{\sum_{i=1}^{m}\left[\left(x_{i}, y_{i}\right)-\bar{f}\right]\left[g\left(x_{i}^{\prime}, y_{i}^{\prime}\right)-\bar{g}\right]}{\sqrt{\sum_{i=1}^{m}\left[f\left(x_{i}, y_{i}\right)-\bar{f}\right]^{2}} \sqrt{\sum_{i=1}^{m}\left[g\left(x_{i}^{\prime}, y_{i}^{\prime}\right)-\bar{g}\right]^{2}}}
$$

where $f\left(x_{i}, y_{i}\right)$ is the grayscale value of the reference image at the point $\left(x_{i}, y_{i}\right)$ and $g\left(x_{i}^{\prime}, y_{i}^{\prime}\right)$ is the grayscale value of the deformed image at the point $\left(x_{i}^{\prime}, y_{i}^{\prime}\right) ; \bar{f}, \bar{g}$ are the average grayscale values of the sub-images in the reference image and the deformed image, respectively.
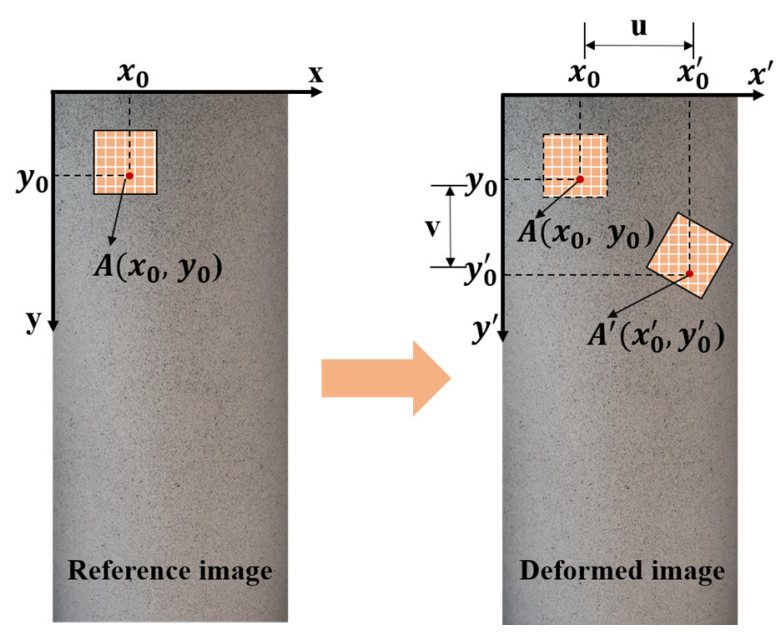

Figure 3. Schematic of the DSCM.

Combined with the DSCM method, secondary uniaxial compression tests were performed on the pre-damaged granite to explore the damage evolution and failure laws. The observation surface of each specimen was uniformly sprayed with a layer of matte white paint, and they were then randomly sprayed with matte black paint. After air drying, a uniaxial compression rigidity testing machine was used for displacement loading at $0.02 \mathrm{~mm} / \mathrm{min}$, and a CCD camera was used for shooting until the specimen was destroyed. The experimental scheme is shown in Figure 4.

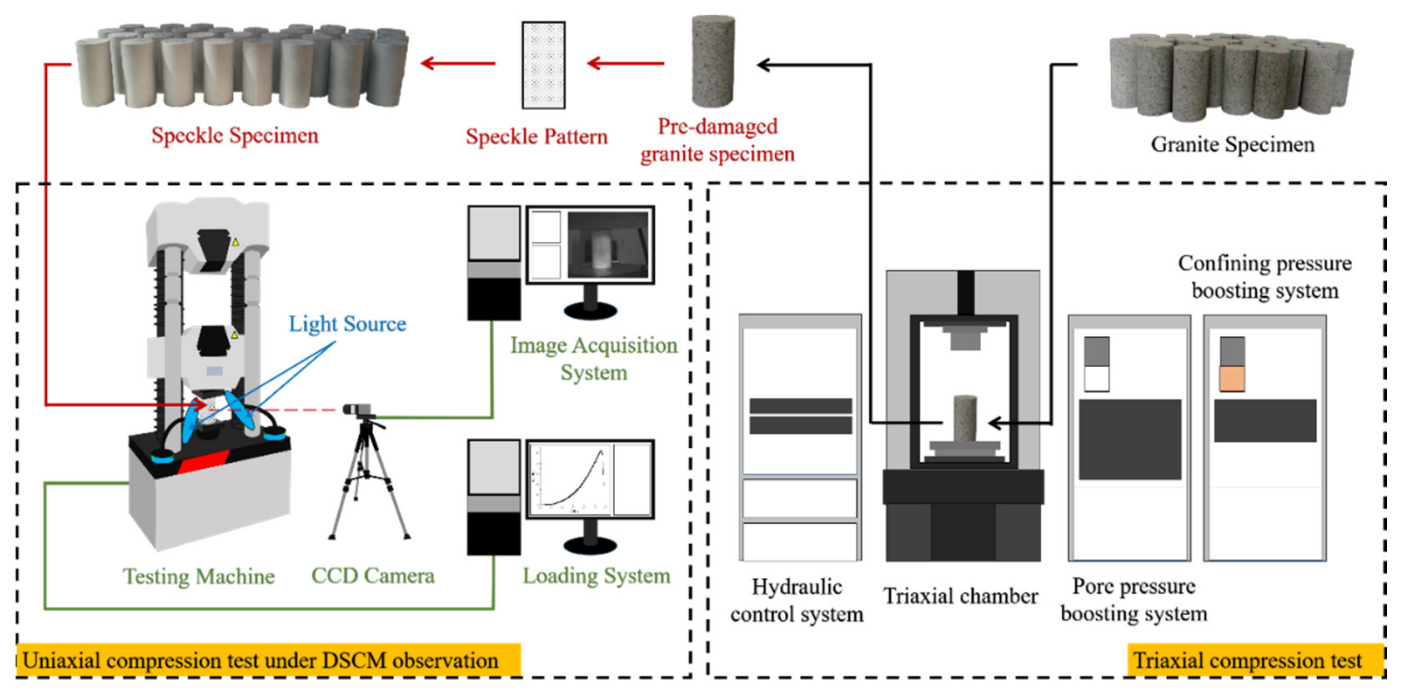

Figure 4. Schematic of experimental scheme. 


\section{Results}

\subsection{Uniaxial Compressive Strength Results for Intact Specimens}

The stress-strain curves of specimens (control group) in group D are illustrated in Figure 5, and the uniaxial compressive strength is $164.20,162.57$, and $167.87 \mathrm{MPa}$, respectively. To study the damage laws of the other groups of pre-damaged granite specimens during uniaxial compression, the uniaxial compressive strength of intact specimens is taken as the average value of $164.88 \mathrm{MPa}$. In addition, it can be seen from the stress-strain curve of uniaxial compression that intact granite belongs to brittle rock, and there is almost no plastic yield stage.

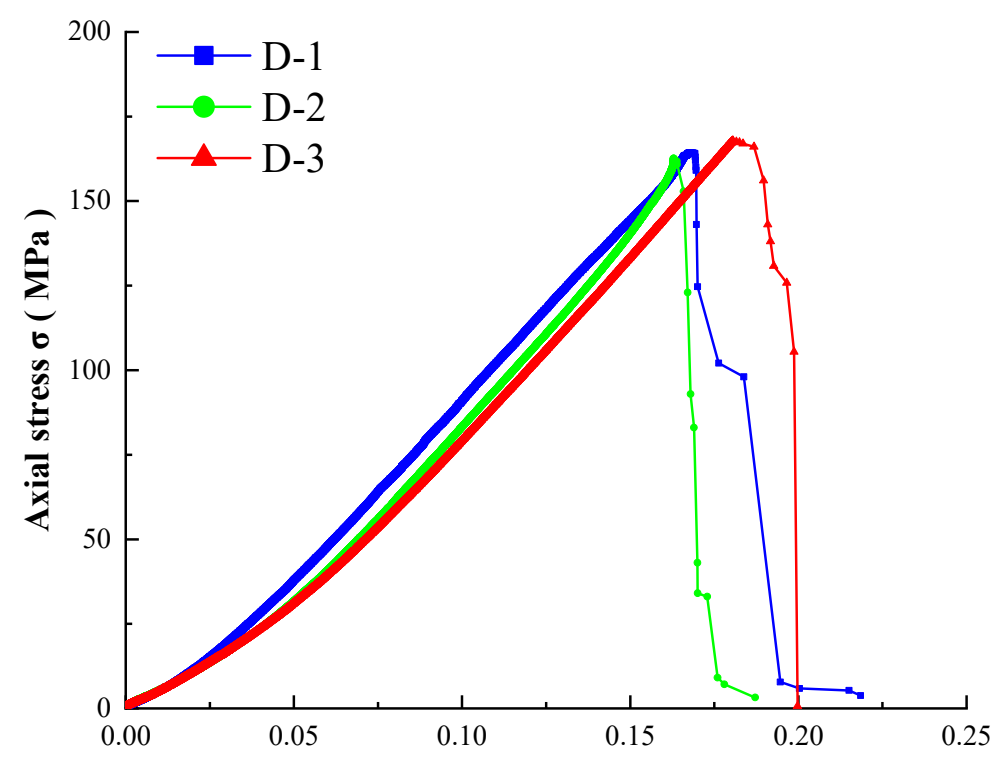

Axial strain \& ( \% )

Figure 5. Stress-strain curve of intact granite.

\subsection{Uniaxial Compressive Strength Results for Pre-Damaged Specimens}

The stress-strain curves for pre-damaged specimens under $50 \mathrm{MPa}$ confining pressure are illustrated in Figure 6. There are significant differences in the axial stress-strain curves after different cycles. The uniaxial compressive strength of pre-damaged specimens with 10 cycles is the largest, and the stress-strain curves showed obvious brittleness, which is very similar to that of the intact granite specimens. With the increase of cycle numbers, the uniaxial compressive strength tended to decrease, and there was strain softening behavior after the peak, which exhibited significant ductility. This indicates that the mechanical properties of pre-damaged specimens in high cycle numbers (20 cycles and 30 cycles) were significantly different from those in low cycle numbers (10 cycles); especially under high cycle numbers, the mechanical properties of pre-damaged specimens decreased significantly. In addition, the stress-strain curve of the pre-damaged specimens has many micro-stress drops, which show pre-peak and post-peak fluctuations, indicating that the pre-damaged specimens were not destroyed once, but destroyed step by step. Because the pre-damage specimen was cyclically loaded and unloaded during triaxial compression pre-damage, it resulted in the repeated initiation and closure of cracks or micro-holes inside the specimen. When cycle numbers increased, the interaction of defects inside the specimen and its damage accumulation effect lead to the expansion of the local deformation area of the specimen under uniaxial compression, greatly reducing the mechanical properties of the specimen. Moreover, when the pre-damaged specimen had good bearing capacity, it is possible that yield failure could have first occurred locally in the specimen. Therefore, a slight stress drop could occur before the specimen fails completely. This result was observed in many studies [24-26]. 


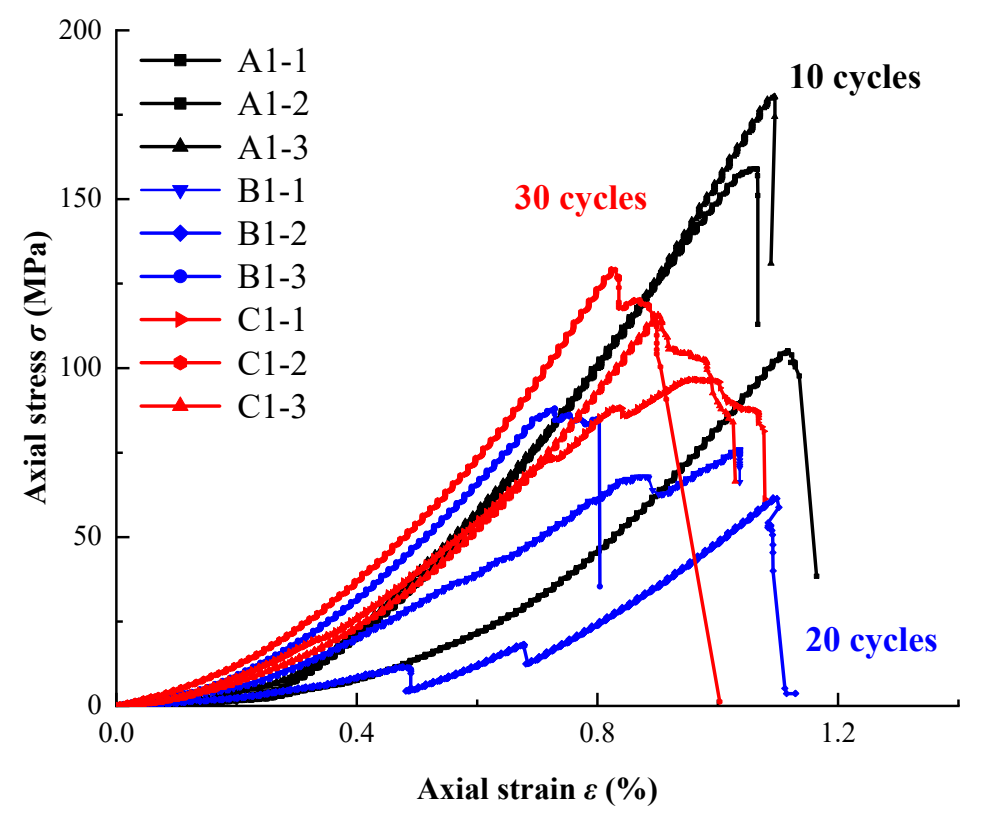

Figure 6. Axial stress-strain curves of pre-damaged specimens with $\sigma_{3}=50 \mathrm{MPa}$.

\subsection{Strength Characteristics of Pre-Damaged Specimens}

Table 3 lists the average uniaxial compressive strength of pre-damaged specimens under different damage conditions, and its relationship with the cycle numbers and confining pressures is shown in Figure 7.

Table 3. The average uniaxial compressive strength of pre-damaged specimens under different damage conditions.

\begin{tabular}{ccccc}
\hline \multirow{2}{*}{$\mathbf{N}^{\mathbf{1}}$} & \multicolumn{4}{c}{$\sigma_{c} \mathbf{( M P a )}$} \\
\cline { 2 - 5 } & $\sigma_{3}=50 \mathbf{M P a}$ & $\sigma_{3}=80 \mathbf{M P a}$ & $\sigma_{3}=100 \mathbf{M P a}$ & $\sigma_{3}=120 \mathbf{M P a}$ \\
\hline 10 & 148.13 & 118.86 & 114.60 & 105.32 \\
20 & 109.21 & 101.03 & 100.87 & 93.04 \\
30 & 113.87 & 107.12 & 85.65 & 53.59 \\
\hline
\end{tabular}

${ }^{1} \sigma_{3}$ is the confining pressure, $\mathrm{N}$ is cycle numbers, and $\sigma_{\mathrm{c}}$ is the average uniaxial compressive strength.

(a)

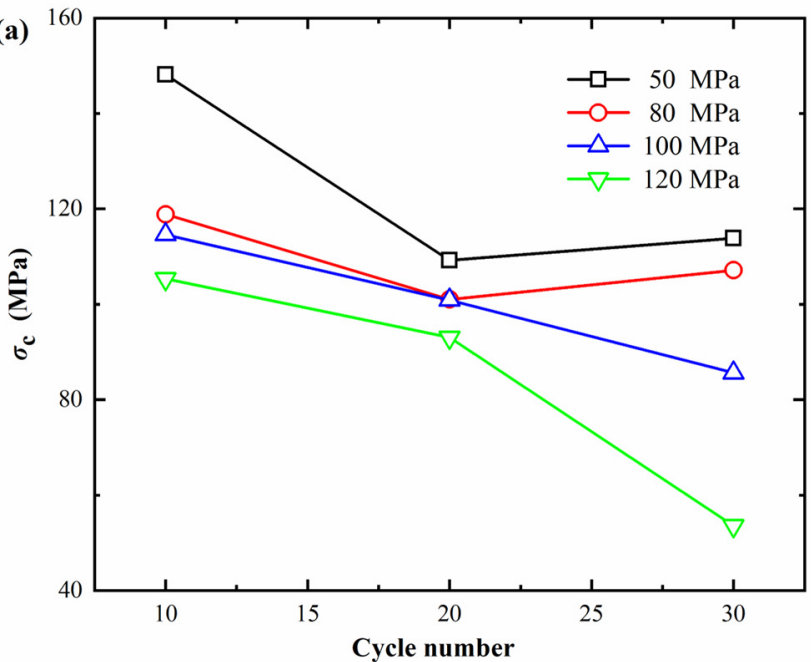

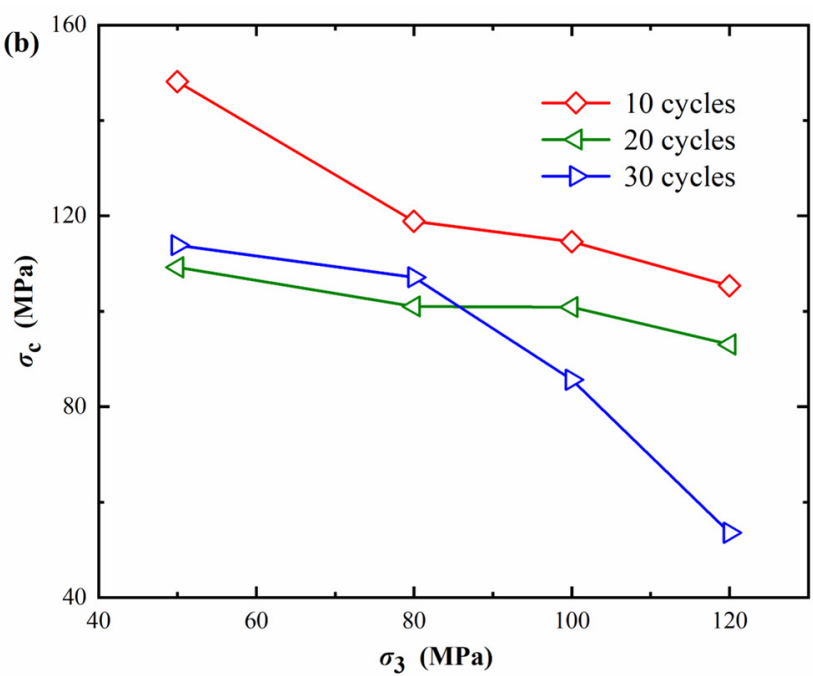

Figure 7. Strength characteristics of pre-damaged specimens. (a) Relationship between $\sigma_{\mathrm{c}}$ and the cycle number; (b) relationship between $\sigma_{\mathrm{c}}$ and $\sigma_{3}$. 
The uniaxial compressive strength of pre-damaged specimens with less than $20 \mathrm{cy}$ cles decreased with the increase of cycle numbers under different confining pressures (Figure 7a). Due to cyclic loading and unloading, cracks were generated inside the specimen, which reduced the bearing capacity of the specimen. Therefore, the uniaxial compressive strength of the specimen was weakened. However, the pre-damaged specimens with more than 20 cycles showed complex strength laws. Under the confining pressures of $50 \mathrm{MPa}$ and $80 \mathrm{MPa}$, the uniaxial compressive strength of the pre-damaged specimens increased with the increase of cycle numbers and decreased with the increase of cycle numbers at $100 \mathrm{MPa}$ and $120 \mathrm{MPa}$. In the high cyclic loading and unloading numbers (more than 20 cycles) of pre-damaged specimen, a large number of cracks inside the specimen was initiated and accumulated. Under the confining pressures of $50 \mathrm{MPa}$ and $80 \mathrm{MPa}$, it is shown that the uniaxial compressive strength of the pre-damaged granite specimen did not always decrease with the increase of the number of cycles. This result differs from that revealed in He et al. [27]. This difference may be due to Griffith cracks, which affect the strength of the specimen according to its size. It has also been shown that if the deviatoric stress of cyclic loading is lower than the fatigue threshold (generally $94 \%$ of rock peak strength), the peak strength obtained by post-monotonic loading may increase [28]. In this test, the upper limit of deviatoric stress cycle was about $93 \%$ of the peak strength of granite, so a slight increase in strength was also possible. Under the confining pressure of $100 \mathrm{MPa}$ and $120 \mathrm{MPa}$, due to the excessive confining pressure, the closed damage cracks inside the specimen started and propagated again, so the uniaxial compressive strength of pre-damaged specimen would continue to weaken. In general, the uniaxial compressive strength of pre-damaged granite specimens is much lower than that of intact granite specimens, which further proves that the bearing capacity of rock decreases after fatigue damage.

The relationship between uniaxial compressive strength and confining pressure is nonlinear (Figure 7b). Under different cycle numbers (10 cycles, 20 cycles, and 30 cycles), the uniaxial compressive strength of pre-damaged specimens decreased with the increase of confining pressure, which decreased by $28.9 \%, 14.8 \%$, and $52.9 \%$, respectively. This shows that the restriction effect of confining pressure on the internal microcrack evolution of the specimen was weakened with the increase of cycle numbers, and the damage of the specimen was mainly dominated by cycle numbers.

\section{Rock Damage Mechanisms and Failure Modes Analysis}

\subsection{Relationship of Damage Variables to Cycle Numbers and Confining Pressures}

Cyclic damage of rocks refers to the existence of internal cracks, micro-holes, and other defects in rocks in a certain pressure field when subjected to a certain cyclic load, resulting in micro-stress concentrations at their ends, and the interaction between microdefects results in the activation of primary cracks or holes and dislocation between rock particles [29]. The meso-damage evolution within the rock is related to cycle numbers and confining pressure, among which the existence of initial confining pressure restricts the generation of micro-defects and particle dislocation. The damage variable D is the description of the meso-damage evolution within the rock [30]. Therefore, the damage variable $\mathrm{D}$ for pre-damaged specimens in this paper is defined as:

$$
\mathrm{D}=\frac{\sigma_{\mathrm{c} 0}-\sigma_{\mathrm{c}}}{\sigma_{\mathrm{c} 0}} \times 100 \%
$$

where $\sigma_{\mathrm{c}}$ is the uniaxial compressive strength of the pre-damaged specimen, $\sigma_{\mathrm{c} 0}$ is the uniaxial compressive strength of the intact specimen, and D is the damage variable of the pre-damaged specimen. It is generally believed that when $D=0$, the rock is in a nondestructive state, at which time $\sigma_{\mathrm{c} 0}=\sigma_{\mathrm{c}}$; when $0<\mathrm{D}<100$, the rock is in the process of deformation failure and is damaged to varying degrees. When $\mathrm{D}=100$, it reaches rock material failure, corresponding to a total loss condition. According to Equation (2), 
the damage law of pre-damaged specimens under different cycle numbers and confining pressures is obtained (Figure 8).
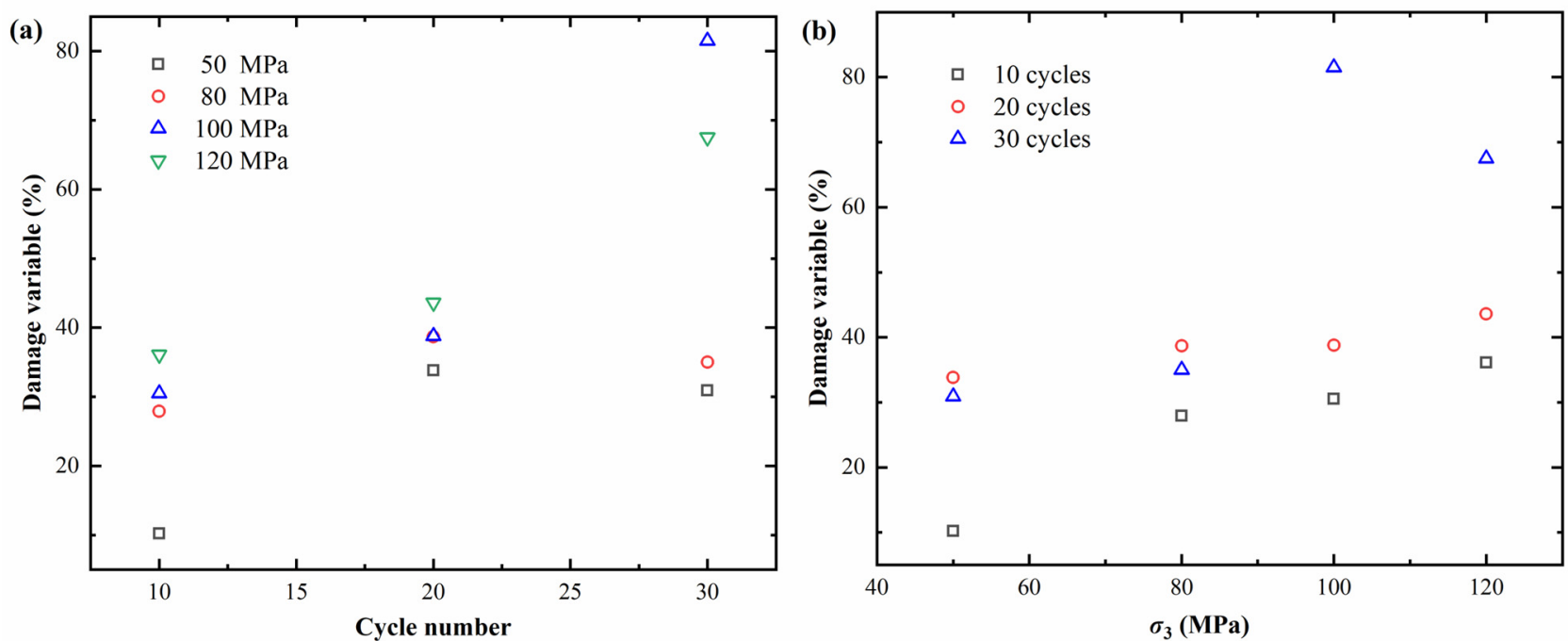

Figure 8. Damage variables of pre-damaged specimens. (a) Relationship between D and cycle numbers; (b) relationship between $\mathrm{D}$ and $\sigma_{3}$.

According to Section 3.1, the uniaxial compressive strength of the intact specimen $\sigma_{\mathrm{c} 0}$ was 164.88 MPa. In Figure 8, as cycle numbers increased, the damage variables for the pre-damaged specimens increased, and the magnitude of the damage changes varied with different confining pressure. At $50 \mathrm{MPa}$ and $80 \mathrm{MPa}$, the increasing rate of the specimen's damage gradually slows down, but there is a certain degree of damage in each cycle. At $100 \mathrm{MPa}$ and $120 \mathrm{MPa}$, the increasing rate of the specimen's damage accelerated with the increase of cycle numbers, with an increase of $167 \%$ and $87 \%$, respectively. The damage characteristics of pre-damaged specimens were not only related to cycle numbers, but also related to the confining pressure. With the increase of confining pressure, the damage variable of pre-damaged specimens after the same number of cycles became higher. When the specimen was subjected to a high number of cyclic loads, the confining pressure effect was not obvious.

\subsection{Damage Evolution Mechanism of Pre-Damaged Specimens}

To further analyze the evolution mechanism (initiation, propagation, and coalescence) of surface cracks in pre-damaged granites, representative specimens were selected and analyzed in detail with the digital speckle correlation method. The surface principal strain cloud maps of the pre-damaged specimen under uniaxial compression are illustrated in Figures 9-11, in which different colors represent different principal strain regions; blue represents low principal strain regions and red represents high principal strain regions. From the principal strain cloud map corresponding to the marks on the stress-strain curve, it can be intuitively seen that there is a one-to-one correspondence between the macroscopic mechanical behavior and the principal strain field during the loading process of pre-damaged specimens. 
(a)

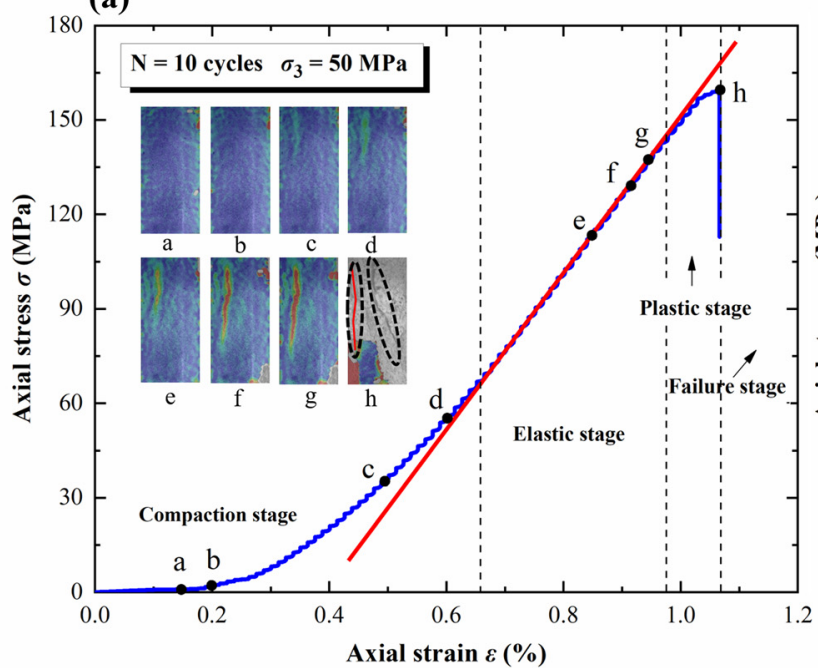

(b)

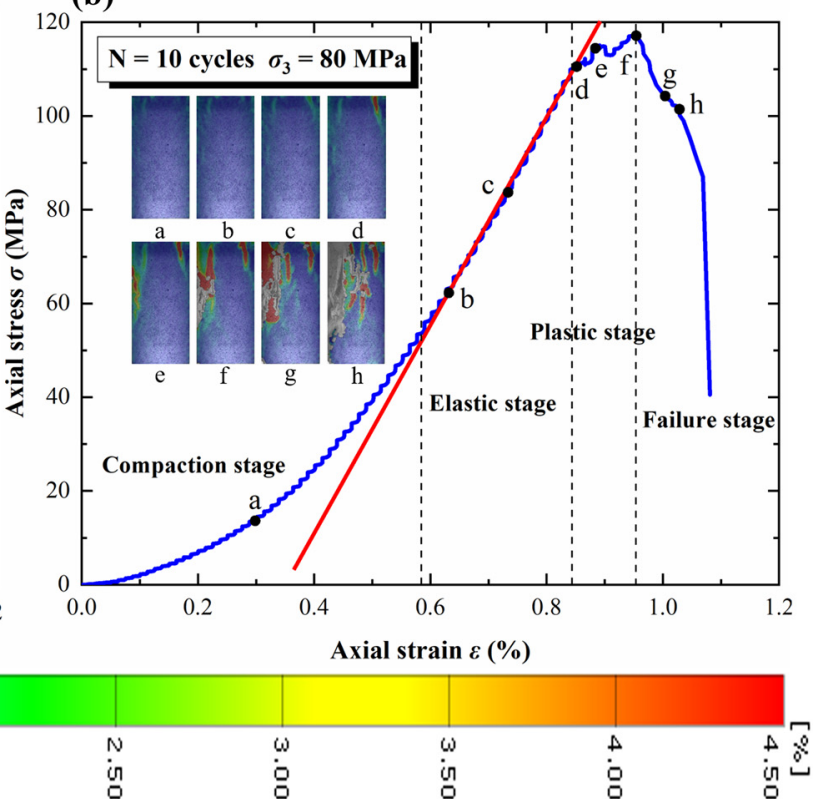

Figure 9. Crack evolution process of pre-damaged specimen after 10 cycles. (a) $\sigma_{3}=50 \mathrm{MPa}$; (b) $\sigma_{3}=80 \mathrm{MPa}$.

(a)

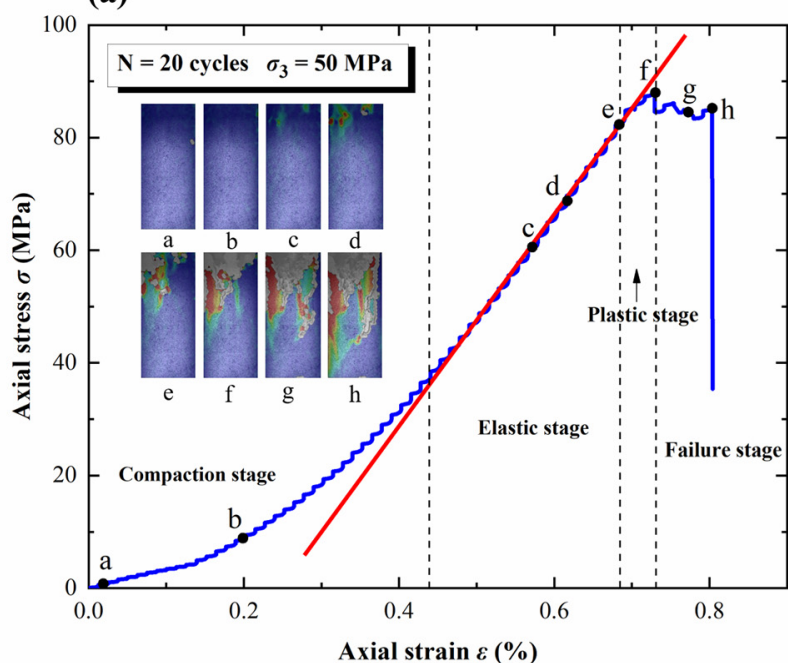

(b)

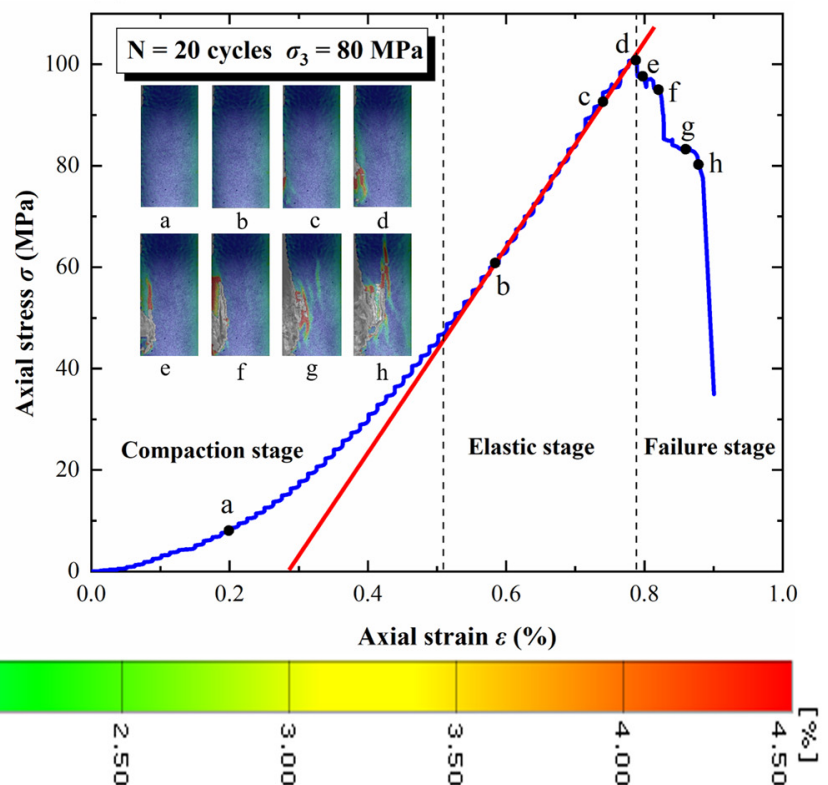

Figure 10. Crack evolution process of pre-damaged specimen after 20 cycles. (a) $\sigma_{3}=50 \mathrm{MPa}$; (b) $\sigma_{3}=80 \mathrm{MPa}$.

The deformation characteristics of the granite specimen after pre-damage show four stages. First, the compaction stage, which has an upward-concave stress-strain curve, is more significant compared to the undamaged granite specimens of group D (Figure 5). This is followed by the elastic stage; the stress-strain curve in this stage is basically straight, as shown in the red line part in Figure 9a. Next is the plastic stage, when the curve is concave, obviously showing the phenomenon of strain increase. Entering the plastic phase means that the rock will have irreversible plastic deformation. Finally, there is the failure stage of the rock. It should be noted that the plastic stage of the granite specimens after pre-damage in this test was very short, and in some cases almost non-existent, as shown in Figures 10b and 11a, which exhibit the characteristics of plastic-brittle failure [31]. In order to combine the processed speckle images, we took the typical representative images of each stage of the granite specimens for analysis. 
(a)

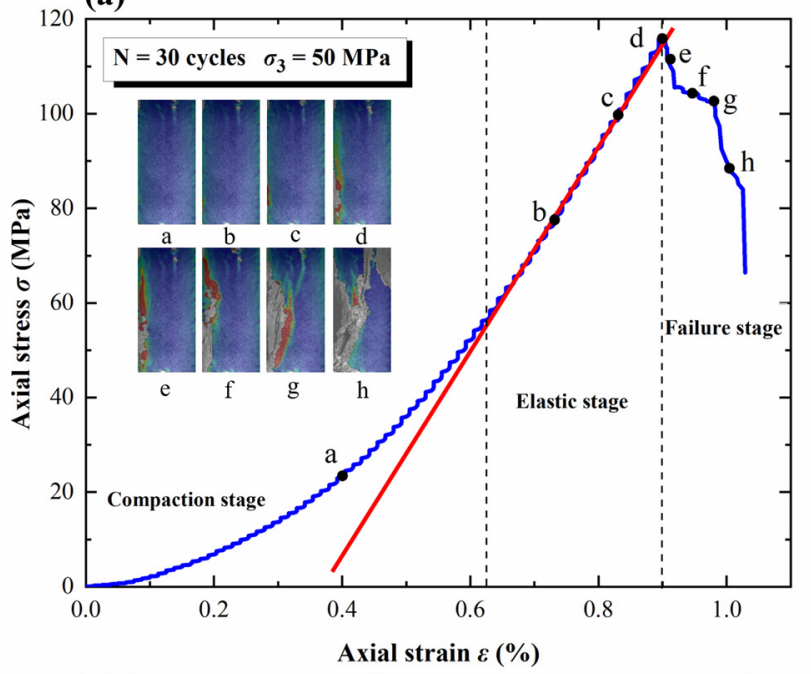

(b)

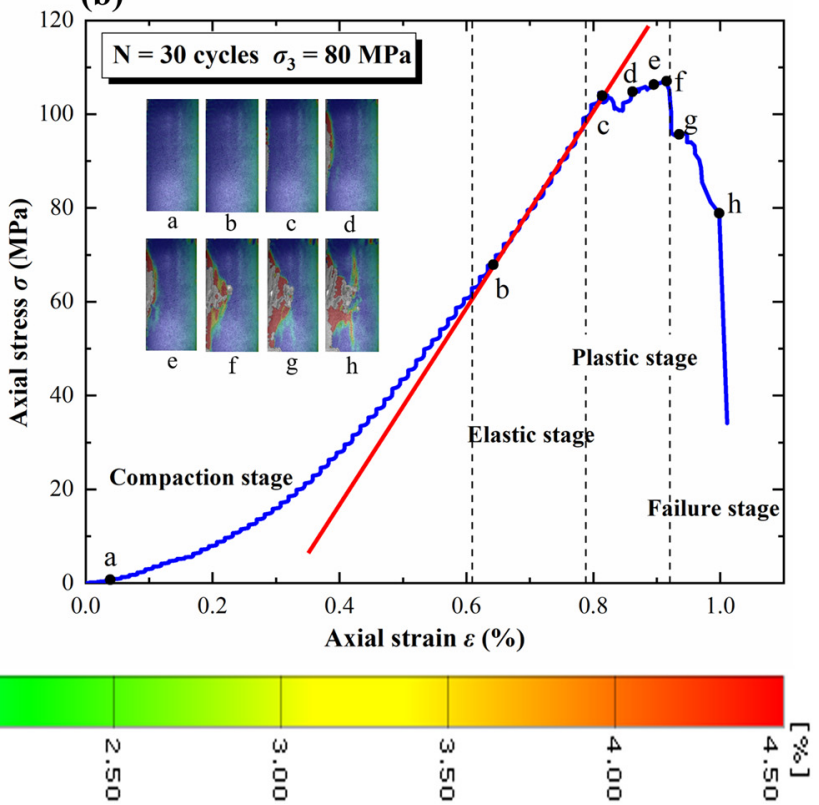

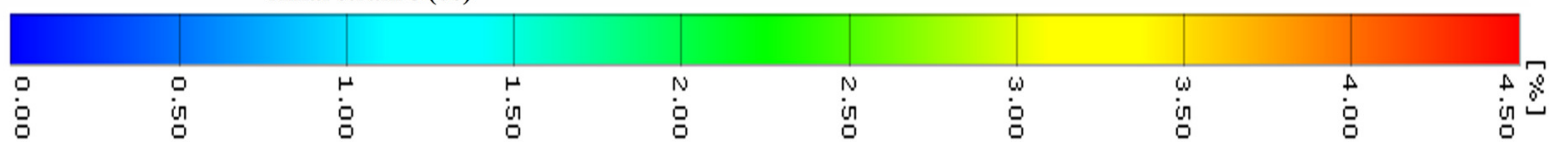

Figure 11. Crack evolution process of pre-damaged specimen after 30 cycles. (a) $\sigma_{3}=50 \mathrm{MPa}$; (b) $\sigma_{3}=80 \mathrm{MPa}$.

At $50 \mathrm{MPa}$ and 10 cycles, the stress at points a-h were $0.6 \% \sigma_{\mathrm{c}}, 1.6 \% \sigma_{\mathrm{c}}, 23.0 \% \sigma_{\mathrm{c}}$ $37.8 \% \sigma_{\mathrm{c}}, 72.6 \% \sigma_{\mathrm{c}}, 85.7 \% \sigma_{\mathrm{c}}, 88.6 \% \sigma_{\mathrm{c}}$, and $100 \% \sigma_{\mathrm{c}}$, respectively (Figure $\left.9 \mathrm{a}\right)$. Points a, b, c, and $\mathrm{d}$ correspond to the compaction stage of the curve; the specimen deformation was small at this time. When loaded to point $c$, an obvious tensile zone was formed in the upper left corner of the specimen, and crack initiation began. Points e, $\mathrm{f}$, and $\mathrm{g}$ correspond to the elastic stage of the curve. When loaded to point $\mathrm{d}-\mathrm{g}$, the tensile band in the upper left corner extended further along the direction of compressive stress until it reached both ends of the specimen. Point $h$ corresponds to the failure stage of the curve, and it is the peak stress point. When loaded to point $h$, a penetrating shear band rapidly formed in the upper right corner of the specimen. At this time, the tensile crack zone on the left side of the specimen was not obvious. Because the surface expanded by the tensile crack was peeled off, the speckle surface could not be captured by the system during image processing, which lead to the failure of recognition and calculation. In the whole process of crack evolution, tensile crack was generated first, then shear crack was generated. In the final failure of the specimen, the tensile crack and shear crack were independent of each other, and there was no coalescence between the cracks. This damage evolution was concentrated in the pre-peak stage, which started from the initial elastic stage to generate cracks, and then propagated crack in the elastic stage and plastic stage, until the specimen was destroyed at the peak, suggesting that the overall evolution was relatively slow.

At $80 \mathrm{MPa}$ and 10 cycles, the stress at points a-h were $11.8 \% \sigma_{\mathrm{c}}, 52.8 \% \sigma_{\mathrm{c}}, 70.5 \% \sigma_{\mathrm{c}}$, $93.8 \% \sigma_{c}, 95.6 \% \sigma_{c}, 100 \% \sigma_{c}, 89.1 \% \sigma_{c}$, and $86.7 \% \sigma_{c}$, respectively (Figure $9 b$ ). Point a corresponds to the compaction stage of the curve, at which time there was a small strain concentration in the upper left corner of the specimen. Points $b$ and $c$ correspond to the elastic stage of the curve, and when loaded to point $\mathrm{c}$, a tensile band began to form at the upper right side of the specimen. Points $d$ and e correspond to the plastic stage of the curve; when loaded to point $d$, the stretch band in the upper right corner deepened further, while the shear band in the upper left corner did not change significantly. When loaded to point e, a wide range of shear bands were formed in the upper left corner of the specimen. Points $\mathrm{f}-\mathrm{h}$ correspond to the failure stage of the curve. When loaded to point $\mathrm{f}$, cracks on the upper left corner of the specimen propagated and penetrate, leading to fracture. After point $f$, the stress drops rapidly. When the stress drops to points $g$ and $h$, the specimen cracks propagated rapidly and coalesced into and penetrated each other, eventually destroying a large area in the upper left corner of the specimen. During 
the whole evolution, numerous tensile cracks and partial shear cracks were initiated, all of which propagated along the direction of compressive stress, and the various cracks interacted with each other, eventually penetrating to form stepped shear cracks, on one side of which the stepped shear cracks generally rupture. This is similar at $100 \mathrm{MPa}$ and $120 \mathrm{MPa}$ confining pressures.

At $50 \mathrm{MPa}$ and 20 cycles, the stress at points a-h were $2.8 \% \sigma_{\mathrm{c}}, 12.2 \% \sigma_{\mathrm{c}}, 70.8 \% \sigma_{\mathrm{c}}$, $81.2 \% \sigma_{c}, 95.8 \% \sigma_{c}, 100 \% \sigma_{c}, 97.5 \% \sigma_{c}$, and $98.9 \% \sigma_{c}$, respectively (Figure $10 \mathrm{a}$ ). Point a and point $\mathrm{b}$ correspond to the compaction stage of the curve, at which time the deformation was relatively uniform. Points $\mathrm{c}-\mathrm{d}$ correspond to the elastic stage of the curve, and when loaded to point $\mathrm{c}$, a strain concentration occurred in the upper left corner of the specimen and the specimen began to deform unevenly. Point e corresponds to the plastic stage of the curve. When loaded to point e, multiple tensile bands initiated above the specimen, all of which propagated along the direction of compressive stress. Points $\mathrm{f}-\mathrm{h}$ correspond to the failure stage of the curve, and when loaded to points $\mathrm{f}-\mathrm{h}$, the tensile crack terminals connected with each other to form two crossed macroscopic shear cracks, namely quasi-coplanar shear cracks. This damage evolution was concentrated near the peak, and it started to initiate cracks in the middle elastic stage, then crack propagation and penetration occurred in the plastic failure stage, and finally destroyed the specimen. The evolution of cracks under other confining pressures (Figure 10b) is similar to Figure $9 \mathrm{~b}$ in that tensile cracks were initiated first, and then the interactions between the tensile cracks merged to form stepped shear cracks.

At $50 \mathrm{MPa}$ and 30 cycles, the stress at points a-h were $20.2 \% \sigma_{\mathrm{c}}, 67.6 \% \sigma_{\mathrm{c}}, 86.9 \% \sigma_{\mathrm{c}}$, $100 \% \sigma_{c}, 90.4 \% \sigma_{c}, 90.2 \% \sigma_{c}, 86.9 \% \sigma_{c}$, and $72.6 \% \sigma_{c}$, respectively (Figure 11 a). Point a corresponds to the compaction stage of the curve, points $b$ and $c$ correspond to the elastic stage of the curve, and the deformation at points $a$ and $b$ is uniform. When loaded to point c, a strain concentration began to form in the lower left corner of the specimen. Points $\mathrm{d}-\mathrm{h}$ correspond to the failure stage of the curve. When loaded to points $\mathrm{d}-\mathrm{f}$, an obvious tensile band formed on the left side of the specimen and began to deform unevenly. When loaded to points $\mathrm{g}-\mathrm{h}$, a shear crack through the specimen formed, which interacted with the tensile crack, forming a " $Y$ " type quasi-coplanar shear crack. This damage evolution was concentrated in the post-peak stage, and the evolution speed was rapid.

At $80 \mathrm{MPa}$ and 30 cycles, the stress at points a-h were $3.8 \% \sigma_{\mathrm{c}}, 64.2 \% \sigma_{\mathrm{c}}, 96.0 \% \sigma_{\mathrm{c}}$, $98.1 \% \sigma_{c}, 99.1 \% \sigma_{c}, 100 \% \sigma_{c}, 89.3 \% \sigma_{c}$, and $73.6 \% \sigma_{c}$, respectively (Figure $11 \mathrm{~b}$ ). Point a corresponds to the compaction stage of the curve, and the deformation was uniform. Point $b$ corresponds to the initial elastic phase of the curve. When loaded to point $b$, the deformation was still uniform. Points c-e correspond to the plastic stage of the curve. When loaded to point $\mathrm{c}$, a stress concentration began to appear on the left side of the specimen with a slight rupture. When loaded to points $\mathrm{d}-\mathrm{e}$, the strain area on the left side of the specimen gradually expanded to form multiple shear cracks, and the strain area was concentrated toward the center of the specimen. Points $\mathrm{f}-\mathrm{h}$ correspond to the failure stage of the curve. Point $f$ was the peak stress point, and when the stress dropped to point $h$, the specimen strain zone exhibited an " $X$ " type quasi-coplanar shear crack. Under the confining pressure of $100 \mathrm{MPa}$ and 30 cycles, the crack evolution process was similar to that of the stepped crack formed above. Under the confining pressure of $120 \mathrm{MPa}$ and 30 cycles, the crack evolution process was a typical quasi-coplanar shear crack evolution process, but its evolution began very early.

DSCM results showed that the surface crack initiation period of the specimen was related to the cycle numbers. The larger the cycle numbers, the surface crack initiation period changed from the elastic stage to the plastic stage, respectively. During the uniaxial compression failure process of pre-damaged specimens, the final macroscopic failure of all specimens was the result of the continuous accumulation of early damage [32]. Due to the influence of the boundary, stress concentration phenomenon usually occurred at the end of the specimen, so the crack initiation was mostly concentrated at the end and always expanded along the direction of the maximum principal strain, leading to the occurrence of 
early damage. In addition, tensile crack was always the earliest crack in the pre-damaged granite specimen, and the initiation of secondary cracks around the tensile crack was mostly the result of the joint action of tension and shear. The shear gradually played a leading role in the crack propagation, and the crack evolution presented a localized phenomenon. These results are consistent with those of crack evolution in [16].

\subsection{Failure Mode of Pre-Damaged Specimens}

Tensile failure is caused by the transverse tensile stress of the failure surface exceeding the maximum tensile stress of the rock, and the crack is called tensile crack. The path of propagation of the tensile crack is smooth. Shear failure is caused by the shear stress of the failure surface exceeding the maximum shear stress of the rock, and the crack is called shear crack. The surface of a shear crack is considerably rougher than that of a tensile crack [33-35].

The pre-damaged specimens showed different failure modes under uniaxial compression. Based on the two basic failure modes of tensile crack and shear crack, the failure modes of the pre-damaged specimen can be divided into three categories: (1) tensile shear failure (mode I), (2) quasi-coplanar shear failure (mode II), and (3) stepped path failure (mode III) (Figure 12).
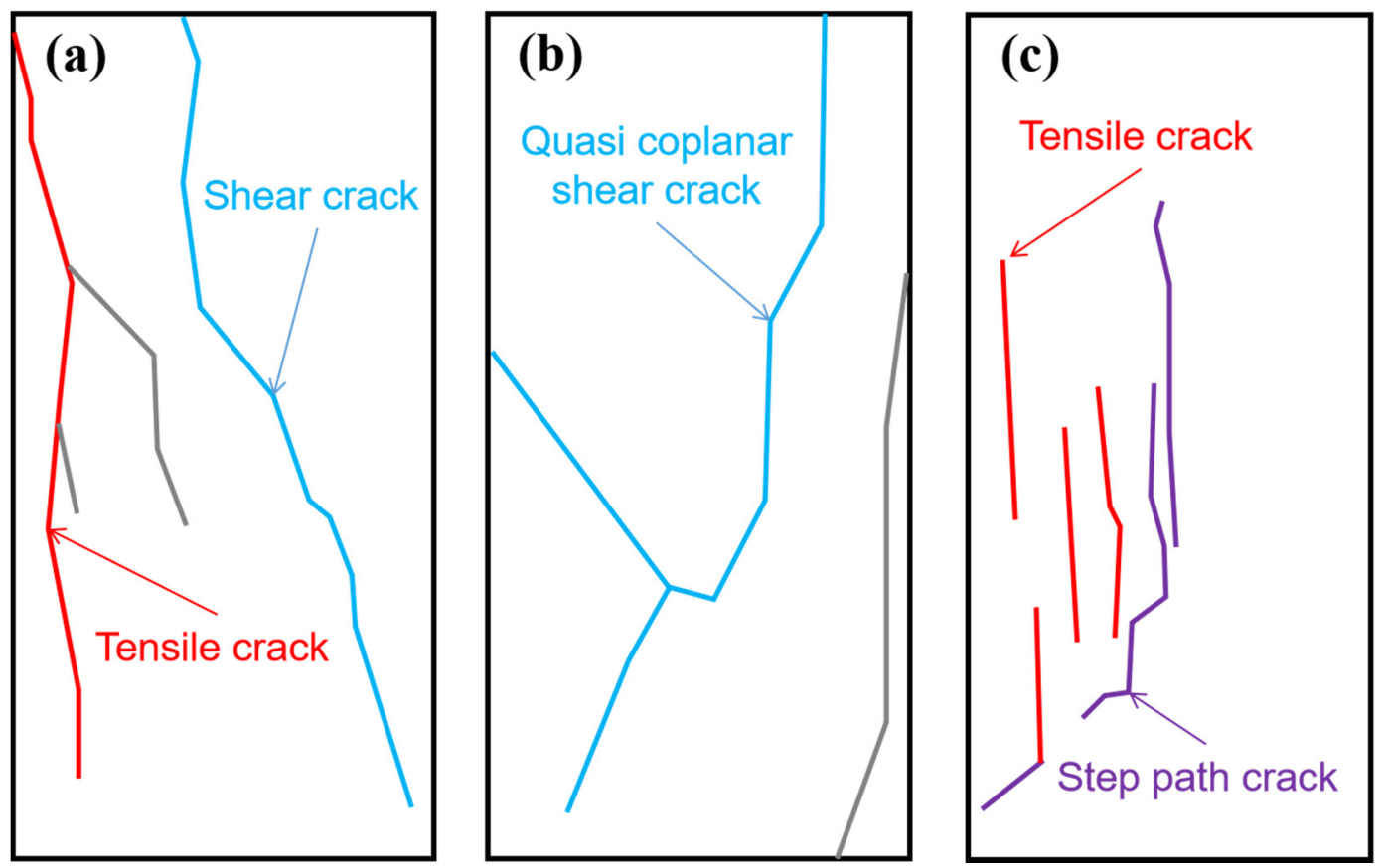

Figure 12. Failure modes of typical specimens. (a) Failure mode I; (b) failure mode II; (c) failure mode III.

(1) Mode I: The main cracks in this failure mode are tensile cracks and shear cracks, and these two main cracks are independent of each other at the time of final failure. No crack coalescence occurs, so this failure mode is called tensile shear failure (Figure 12a). The red line is a tensile crack, the blue line is a shear crack, and the gray line is secondary shear cracks in Figure 12a. The final failure in this mode will cause spalling on the tensile crack or shear crack surface, and the overall degree of damage is small. This failure mode is also identified in $[33,36]$, which is called mixed coalescence mode.

(2) Mode II: The main cracks in this failure mode are two intersecting shear cracks, so this mode is called quasi-coplanar shear failure (Figure 12b). The blue line is a quasicoplanar shear crack, and the gray line is a shear secondary crack in Figure 12b. The damage in this mode is generally marked by peeling from its conjugate surface or 
collapse, and the degree of damage is large. Such quasi-conjugate or single shear plane failure results have been reported in [37].

(3) Mode III: The main cracks in this failure mode are tensile cracks. Because multiple tensile cracks interact, propagate and coalescence to form a shear crack in a stepped path, this mode is called a stepped path failure (Figure 12c). The purple line is a step path crack, and the blue line is a tensile crack in Figure 12c. The main feature of this failure mode is that there are generally multiple groups of parallel tensile cracks above or below the step. Failure mode III in this mode generally shows layers of peeling in the tensile crack area, and the degree of damage is relatively large. This result is consistent with those of a granite specimen that contains multiple pre-existing holes in [33].

Both cycle numbers and confining pressure affect the failure mode of pre-damaged specimens to varying degrees. Table 4 summarizes failure modes of pre-damaged specimens under uniaxial compression, with red lines representing tensile cracks, blue lines representing shear cracks, and purple lines representing stepped cracks. When confining pressure is $50 \mathrm{MPa}$, pre-damaged specimens with 10 cycles belong to mode I, and specimens with 20 and 30 cycles belong to mode II. When confining pressure is $80 \mathrm{MPa}$, predamaged specimens with 10 cycles belong to the transition failure mode I-III, specimens with 20 cycles belong to failure mode III, and specimens with 30 cycles belong to failure mode II. When confining pressure is $100 \mathrm{MPa}$, all pre-damaged specimens belong to mode III. When confining pressure is $120 \mathrm{MPa}$, pre-damaged specimens with 10 and 20 cycles belong to failure mode III, and specimens with 30 cycles belong to failure mode II.

Table 4. Failure mode of pre-damaged specimens under uniaxial compression.

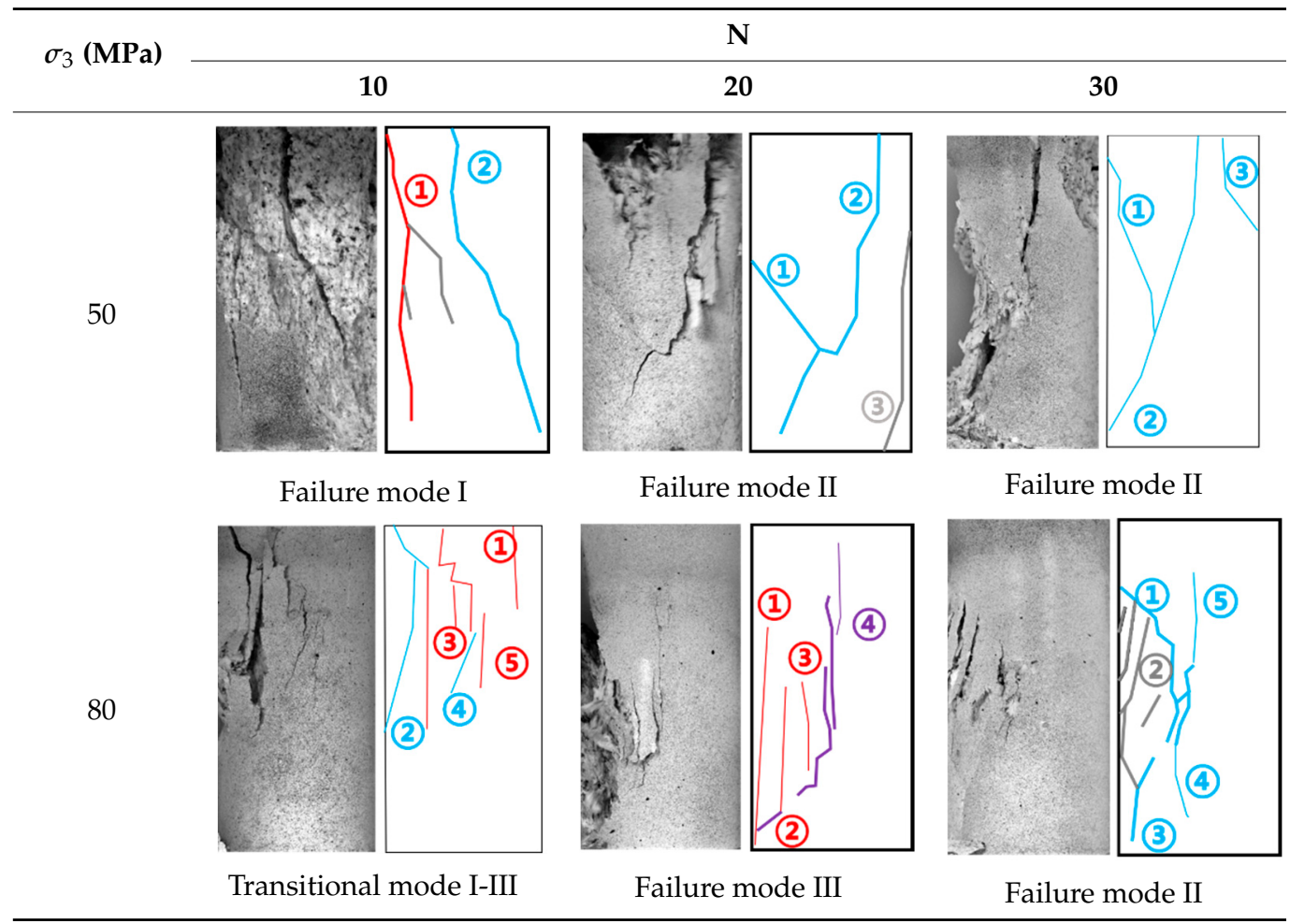


Table 4. Cont.

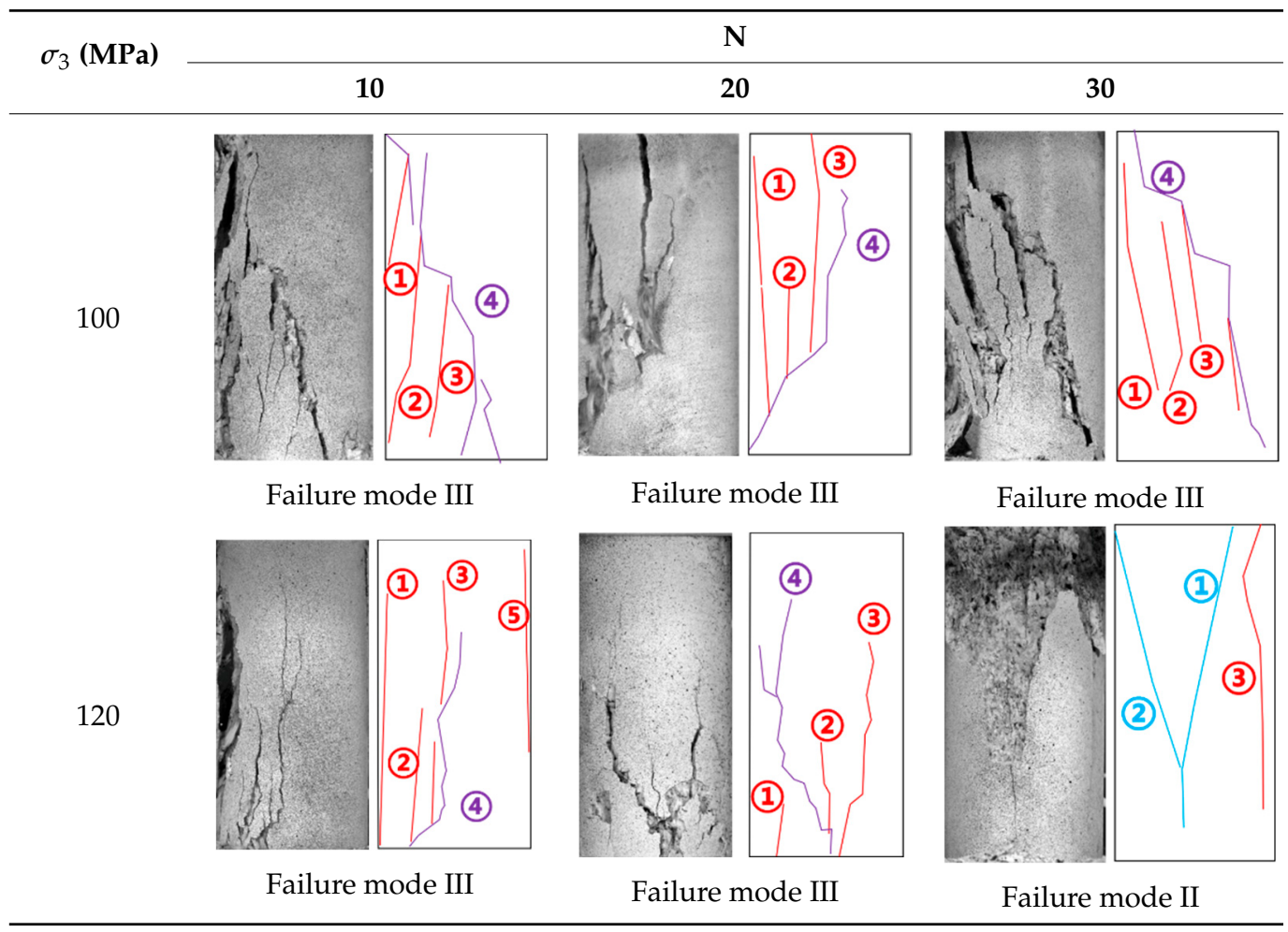

\section{Conclusions}

(1) The mechanical properties of granite specimens that undergo high cycle pre-damage are significantly different from those of their low cycle pre-damage specimens. The mechanical properties of the high cycle pre-damaged specimens decreased significantly. Under uniaxial compression, the pre-damaged specimens showed complex strength characteristics, and uniaxial compressive strength presents a non-linear relationship with cycle numbers and confining pressures. Damage to pre-damaged specimens was primarily due to the strength weakening effect caused by cycle numbers.

(2) The damage variables of pre-damaged specimens positively correlate with the cycle numbers and confining pressure. Damage to the pre-damaged specimens continues to increase with increasing cycle numbers, and the magnitude of damage varied with various confining pressure. The greater the confining pressure, the greater the damage variable in pre-damaged specimens. When specimens were subjected to high cycle numbers, the confining pressure restriction effect was not obvious.

(3) The evolution laws of uniaxial compression damage propagation in pre-damaged specimens showed differences and obvious localization phenomenon under different cycle numbers and confining pressures. The number of initial cracks was less at low cycle numbers. However, the number of initial cracks was large under high cycle numbers, and they coalesced with each other to form stepped shear cracks. Tensile cracks were always the earliest cracks to appear in pre-damaged granite specimens, and the greater the cycle numbers, the more concentrated the crack initiation was in the plastic deformation stage.

(4) There are three uniaxial compression failure modes for pre-damaged specimens, namely tensile shear failure (mode I), quasi-coplanar shear failure (mode II), and stepped path failure (mode III). The failure modes of pre-damaged specimens are related to confining pressure. Under different pre-damage stress environments with high confining pressures, the failure modes are dominated by Mode II and Mode III, respectively. 
Author Contributions: Conceptualization, J.H. and D.Y.; methodology, D.Y.; validation, D.Y., G.W. and X.X.; data curation, P.Z. and F.Z.; writing-original draft preparation, P.Z.; writing-review and editing, J.H. and D.Y.; visualization, P.Z., S.M. and R.X.; supervision, J.H.; funding acquisition, J.H. All authors have read and agreed to the published version of the manuscript.

Funding: This research was funded by the National Key Research and Development Program of China (2017YFC0602901); the National Natural Science Foundation of China (41672298); and the Central South University Postgraduate Independent Exploration and Innovation Project Fund (2021zzts0872).

Institutional Review Board Statement: Not applicable.

Informed Consent Statement: Not applicable.

Data Availability Statement: All data, models, and code generated or used during the study appear in the submitted article.

Conflicts of Interest: The authors declare no conflict of interest.

\section{References}

1. Wang, Y.T.; Zhou, X.P.; Xu, X. Numerical simulation of propagation and coalescence of flaws in rock materials under compressive loads using the extended non-ordinary state-based peridynamics. Eng. Fract. Mech. 2016, 248-273. [CrossRef]

2. Singh, P.K. Blast vibration damage to underground coal mines from adjacent open-pit blasting. Int. J. Rock Mech. Min. Sci. 2002, 39, 959-973. [CrossRef]

3. Vaneghi, R.G.; Ferdosi, B.; Okoth, A.D.; Kuek, B. Strength degradation of sandstone and granodiorite under uniaxial cyclic loading. J. Rock Mech. Geotech. Eng. 2018, 10, 117-126. [CrossRef]

4. Zhou, Z.L.; Wang, H.Q.; Cai, X.; Zang, H.Z.; Chen, L.; Liu, F. Bearing characteristics and fatigue damage mechanism of multi-pillar system subjected to different cyclic loads. J. Cent. South Univ. 2020, 27, 542-553. [CrossRef]

5. Fan, X.; Kulatilake, P.H.S.W.; Chen, X. Mechanical behavior of rock-like jointed blocks with multi-non-persistent joints under uniaxial loading: A particle mechanics approach. Eng. Geol. 2015, 190, 17-32. [CrossRef]

6. Hu, J.H.; Yang, D.J. Meso-damage evolution and mechanical characteristics of low-porosity sedimentary rocks under uniaxial compression. Trans. Nonferr. Met. Soc. China 2020, 30, 1071-1077. [CrossRef]

7. Xiao, J.Q.; Ding, D.X.; Jiang, F.L.; Xu, G. Fatigue damage variable and evolution of rock subjected to cyclic loading. Int. J. Rock Mech. Min. Sci. 2010, 47, 461-468. [CrossRef]

8. Bagde, M.N.; Petroš, V. Fatigue and dynamic energy behaviour of rock subjected to cyclical loading. Int. J. Rock Mech. Min. Sci. 2009, 46, 200-209. [CrossRef]

9. Chen, Y.Q.; Watanabe, K.; Kusuda, H.; Kusaka, E.; Mabuchi, M. Crack growth in Westerly granite during a cyclic loading test. Eng. Geol. 2011, 117, 189-197. [CrossRef]

10. Zhang, P.; Xu, J.G.; Li, N. Fatigue properties analysis of cracked rock based on fracture evolution process. J. Cent. South Univ. Technol. 2008, 15, 95-99. [CrossRef]

11. Fuenkajorn, K.; Phueakphum, D. Effects of cyclic loading on mechanical properties of Maha Sarakham salt. Eng. Geol. 2010, 112, 43-52. [CrossRef]

12. Taheri, A.; Yfantidis, N.; Olivares, C.L.; Connelly, B.J.; Bastian, T.J. Experimental Study on Degradation of Mechanical Properties of Sandstone under Different Cyclic Loadings. Geotech. Test. J. 2016, 39, 673-687. [CrossRef]

13. Jia, C.J.; Xu, W.Y.; Wang, R.B.; Wang, W.; Zhang, J.C.; Yu, J. Characterization of the deformation behavior of fine-grained sandstone by triaxial cyclic loading. Constr. Build. Mater. 2018, 162, 113-123. [CrossRef]

14. Wang, Z.C.; Li, S.C.; Qiao, L.P.; Zhao, J.G. Fatigue Behavior of Granite Subjected to Cyclic Loading under Triaxial Compression Condition. Rock Mech. Rock Eng. 2013, 46, 1603-1615. [CrossRef]

15. Liu, E.L.; Huang, R.Q.; He, S.M. Effects of Frequency on the Dynamic Properties of Intact Rock Samples Subjected to Cyclic Loading under Confining Pressure Conditions. Rock Mech. Rock Eng. 2011, 45, 89-102. [CrossRef]

16. Hu, J.H.; Wen, G.P.; Lin, Q.B.; Cao, P.; Li, S. Mechanical properties and crack evolution of double-layer composite rock-like specimens with two parallel fissures under uniaxial compression. Theor. Appl. Fract. Mech. 2020, 108, 102610-102621. [CrossRef]

17. Xie, Z.Z.; Zhang, N.; Meng, F.F.; Han, C.L.; An, Y.P.; Zhu, R.J. Deformation Field Evolution and Failure Mechanisms of Coal-Rock Combination Based on the Digital Speckle Correlation Method. Energies 2019, 12, 2511. [CrossRef]

18. Tan, Y.L.; Guo, W.Y.; Zhao, T.B.; Yu, F.H.; Huang, B.; Huang, D.M. Influence of Fissure Number on the Mechanical Properties of Layer-Crack Rock Models under Uniaxial Compression. Adv. Civ. Eng. 2018, 2018, 1-12. [CrossRef]

19. Sun, Q.; Cai, C.; Zhang, S.K.; Tian, S.; Li, B.; Xia, Y.J.; Sun, Q.W. Study of localized deformation in geopolymer cemented coal gangue-fly ash backfill based on the digital speckle correlation method. Constr. Build. Mater. 2019, 215, 321-331. [CrossRef]

20. Cao, R.H.; Lin, H.; Cao, P. Strength and failure characteristics of brittle jointed rock-like specimens under uniaxial compression: Digital speckle technology and a particle mechanics approach. Int. J. Min. Sci. Technol. 2018, 28, 669-677. [CrossRef] 
21. Li, X.P.; Wang, B. Research on Distribution Rule of Geostress in Deep Rock in Chinese Mainland. Adv. Mater. Res. 2011, 243-249, 2116-2122. [CrossRef]

22. Zhou, Z.L.; Cai, X.; Ma, D.; Cao, W.Z.; Chen, L.; Zhou, J. Effects of water content on fracture and mechanical behavior of sandstone with a low clay mineral content. Eng. Fract. Mech. 2018, 47-65. [CrossRef]

23. Ma, S.P.; Wang, L.G.; Jin, G.C. Damage evolution inspection of rock using digital speckle correlation method (DSCM). Exp. Mech. Nano Biotech. 2006, 326-328, 1117-1120. [CrossRef]

24. Liu, L.; Xu, W.Y.; Zhao, L.Y.; Zhu, Q.Z.; Wang, R.B. An experimental and numerical investigation of the mechanical behavior of granite gneiss under compression. Rock Mech. Rock Eng. 2017, 50, 499-506. [CrossRef]

25. Huang, B.; Lu, W. Experimental investigation of the uniaxial compressive behavior of thin building granite. Constr. Build. Mater. 2021, 267. [CrossRef]

26. Yang, S.Q.; Huang, Y.H.; Tian, W.L.; Yin, P.F.; Jing, H.W. Effect of high temperature on deformation failure behavior of granite specimen containing a single fissure under uniaxial compression. Rock Mech. Rock Eng. 2019, 52, 2087-2107. [CrossRef]

27. He, C.; Yang, J. Laboratory study of dynamic mechanical characteristic of granite subjected to confining pressure and cyclic blast loading. Lat. Am. J. Solids Struct. 2018, 15, 1-16. [CrossRef]

28. Taheri, A.; Royle, A.; Yang, Z.; Zhao, Y. Study on variations of peak strength of a sandstone during cyclic loading. Geomech. Geophys. Geo-Energy Geo-Resour. 2016, 2, 1-10. [CrossRef]

29. Wu, F.; Chen, J.; Zou, Q.L. A nonlinear creep damage model for salt rock. Int. J. Damage Mech. 2018, 28, 758-771. [CrossRef]

30. Shang, J.L.; Hu, J.H.; Zhou, K.P.; Luo, X.W. Porosity increment and strength degradation of low-porosity sedimentary rocks under different loading conditions. Int. J. Rock Mech. Min. Sci. 2015, 75, 216-223. [CrossRef]

31. Liu, G.; Xiao, F.K.; Guo, Z.B.; Chi, X.H.; Jiang, Y.N.; Yu, H.; Hou, Z.Y.; Zhao, R.X. Plastic characteristics of rock under point load. Sci. Technol. Eng. 2018, 18, 217-222.

32. Amitrano, D. Rupture by damage accumulation in rocks. Int. J. Fract. 2006, 139. [CrossRef]

33. Huang, Y.H.; Yang, S.Q.; Tian, W.L. Cracking process of a granite specimen that contains multiple pre-existing holes under uniaxial compression. Fatigue Fract. Eng. Mater. Struct. 2019, 42, 1341-1356. [CrossRef]

34. Shi, G.C.; Yang, X.J.; Yu, H.C.; Zhu, C. Acoustic emission characteristics of creep fracture evolution in double-fracture fine sandstone under uniaxial compression. Eng. Fract. Mech. 2019, 210, 13-28. [CrossRef]

35. Lee, H.; Jeon, S. An experimental and numerical study of fracture coalescence in pre-cracked specimens under uniaxial compression. Int. J. Solids Struct. 2011, 48, 979-999. [CrossRef]

36. Liu, J.P.; Li, Y.H.; Xu, S.; Jin, C.Y.; Liu, Z.S. Moment tensor analysis of acoustic emission for cracking mechanisms in rock with a pre-cut circular hole under uniaxial compression. Eng. Fract. Mech. 2015, 135, 206-218. [CrossRef]

37. Lin, P.; Wong, R.H.C.; Tang, C.A. Experimental study of coalescence mechanisms and failure under uniaxial compression of granite containing multiple holes. Int. J. Rock Mech. Min. Sci. 2015, 77, 313-327. [CrossRef] 